\title{
Investigation of Composite Torsion Shaft for Torsional Buckling Analysis using Finite Element Analysis.
}

\author{
${ }^{1}$ Sagar D. Patil, ${ }^{2}$ Prof. D.S.Chavan, ${ }^{3}$ Prof. M.V.Kavade \\ ${ }^{1,2,3}$ Rajarambapu Institute of Tecnology, Sakharale.
}

\begin{abstract}
The overall objective of this paper is to design and analyze a composite drive shaft for power transmission applications. A one-piece drive shaft for rear wheel drive automobile was designed optimally using E-Glass/Epoxy and High modulus (HM) Carbon/Epoxy composites. In this paper an Analytical and ANSYS Software has been successfully applied to minimize the weight of shaft which is subjected to the constraints such as torque transmission, Static Structural capacities. The results of Analytical Analysis are used to perform Torsional Buckling analysis using ANSYS software. The results show the stacking sequence and fiber angle orientation of shaft strongly affects Buckling strength of shaft.
\end{abstract}

\section{Introduction}

A composite material or a compound is a mixture of two or more distinct constituents all of which are present in reasonable proportions and have different properties so that the composite properties exhibited are the combination of the best qualities of their constituents and also some qualities that neither of their constituents possesses. Plastic is not a composite because it is compound. An alloy is not composite because it is a homogeneous mixture. Following are some of the properties that can be improved by forming a composite material Strength, Stiffness, Corrosion resistance, Wear resistance, Weight, Fatigue failure. Naturally, not all of these properties are improved at the same time nor is there usually any requirement to do so. In fact, some of the properties are in conflict with one another, e.g., thermal insulation versus thermal conductivity.

\section{Literature Review}

M.A. Badie et al. [1] examines the effect of fiber orientation angles and stacking sequence on the torsional stiffness,natural frequency, buckling strength, fatigue life and failure modes of composite tubes. Finite element analysis (FEA) has been used to predict the fatigue life of composite drive shaft (CDS) using linear dynamic analysis for different stacking sequence. Experimental program on scaled woven fabric composite models was carried out to investigate the torsional stiffness. FEA results showed that the natural frequency increases with decreasing fiber orientation angles.

Mahmood M. Shokrieh et al. [2] has done Shear buckling of composite drive shaft under torsion was performed using FEM. The commercial finite element package ANSYS was used for the solution of the problem. In order to achieve model the composite shaft, the shell 99 element is used and the shaft is subjected to torsion. The shaft is fixed at one end in axial, radial and tangential directions and is subjected to torsion at the other end. After performing a static analysis of the shaft, the stresses are saved in a file to calculate the buckling load. The output of the buckling analysis is a load coefficient which is the ratio of the buckling load to the static load. S.A. Mutasher [3] investigates the maximum torsion capacity of the composite shaft for different winding angle, number of layers and stacking sequences. The Composite shaft consists of aluminum tube wound outside by E-glass and carbon fibers/epoxy composite. The finite element method has been used to analyze the hybrid shaft under static torsion. ANSYS finite element software was used to perform the numerical analysis for the shaft. The specimen was analyzed. Elasto-plastic properties were used for aluminum tube and linear elastic for composite materials. The results show that the static torque capacity is significantly affected by changing the winding angle, stacking sequences and number of layers.

Y.A. Khalid et al [4] studied a bending fatigue analysis was carried out for composite drive shafts. The shafts used were fabricated using filament winding technique. Glass fiber with a matrix of epoxy resin and hardener were used to construct the external composite layers needed. Four cases were studied using aluminum tube wounded by different layers of composite materials and different stacking sequence or fiber orientation angles. The failure mode for all the hybrid shafts was identified.

III. Analytical Analysis Of Composite Shaft

$\frac{1}{E_{11}}=\frac{\cos ^{4} \theta}{E_{x y}}+\frac{\sin ^{4} \theta}{E_{y y}}+\frac{1}{4}\left(\frac{1}{G_{x y}}-\frac{2 \mu_{x y}}{E_{x x}}\right) \sin ^{2} 2 \theta$

$\frac{1}{E_{22}}=\frac{\sin ^{4} \theta}{E_{x x}}+\frac{\cos ^{4} \theta}{E_{y y}}+\frac{1}{4}\left(\frac{1}{G_{x y}}-\frac{2 \mu_{x y}}{E_{x x}}\right) \sin ^{2} 2 \theta$ 
$\frac{1}{G_{12}}=\frac{1}{E_{x x}}+\frac{2 \mu_{x y}}{E_{x x}}+\frac{1}{E_{y y}}-\left(\frac{1}{E_{x x}}+\frac{2 \mu_{x y}}{E_{x x}}+\frac{1}{E_{y y}}-\frac{1}{G_{x y}}\right) \cos ^{2} 2 \theta$

$\mu_{12}=E_{11}\left(\frac{\mu_{x y}}{E_{x x}}\left(\sin ^{4} \theta+\cos ^{4} \theta\right)-\left[\frac{1}{E_{11}}+\frac{1}{E_{22}}-\frac{1}{G_{12}}\right] \sin ^{2} \theta \cos ^{2} \theta\right)$

$\mu_{21}=\frac{E_{22}}{E_{11}} \mu_{12}$

\subsection{Stiffness matrix:}

$Q=\left[\begin{array}{ccc}Q_{11} & Q_{12} & 0 \\ Q_{21} & Q_{22} & 0 \\ 0 & 0 & Q_{66}\end{array}\right]$

$Q_{11}=\frac{E_{11}}{1-\mu_{12} \mu_{21}}$

$Q_{22}=\frac{E_{22}}{1-\mu_{12} \mu_{21}}$

$Q_{12}=Q_{21}=\frac{\mu_{12} E_{22}}{1-\mu_{12} \mu_{21}}=\frac{\mu_{21} E_{11}}{1-\mu_{12} \mu_{21}}$

$Q_{66}=G_{12}$

\section{2 $\bar{Q}$ Matrix}

Using trigonometric identities, Tsai and Pagano have shown that the Elements in the $\bar{Q}$ matrix can be written as,

$\bar{Q}=\left[\begin{array}{lll}\bar{Q}_{11} & \bar{Q}_{12} & \bar{Q}_{16} \\ \bar{Q}_{21} & \bar{Q}_{22} & \bar{Q}_{26} \\ \bar{Q}_{31} & \bar{Q}_{32} & \bar{Q}_{66}\end{array}\right]$

Where,

$\overline{Q_{11}}=Q_{11} \cos ^{4} \theta+2\left(Q_{12}+2 Q_{66}\right) \sin ^{2} \theta \cos ^{2} \theta+Q_{22} \sin ^{4} \theta$

$\overline{Q_{12}}=\left(Q_{11}+Q_{22}-4 Q_{66}\right) \sin ^{2} \theta \cos ^{2} \theta+Q_{12}\left(\sin ^{4} \theta+\cos ^{4} \theta\right)$

$\frac{\overline{Q_{22}}}{Q_{12}}=Q_{11} \sin ^{4} \theta+2\left(Q_{12}+2 Q_{66}\right) \sin ^{2} \theta \cos ^{2} \theta+Q_{22} \cos ^{4} \theta$

$\underline{\underline{Q_{16}}}=\left(Q_{12}-Q_{12}-2 Q_{66}\right) \sin \theta \cos ^{3} \theta+\left(Q_{12}-Q_{22}+2 Q_{66}\right) \sin ^{3} \theta \cos \theta$

$\overline{Q_{26}}=\left(Q_{11}-Q_{12}-2 Q_{66}\right) \sin ^{3} \theta \cos \theta+\left(Q_{12}-Q_{22}+2 Q_{66}\right) \sin \theta \cos ^{3} \theta$

$\overline{Q_{66}}=\left(Q_{11}+Q_{22}-2 Q_{12}-2 Q_{66}\right) \sin ^{2} \theta \cos ^{2} \theta+Q_{66}\left(\sin ^{4} \theta+\cos ^{4} \theta\right)$

\subsection{Lamina S/D/F-Strain Behavior}

The S/D/F-strain relations in principal material coordinates for a lamina of an orthotropic material under plane $\mathrm{S} / \mathrm{D} / \mathrm{F}$ are:

$\left[\begin{array}{l}\sigma_{1} \\ \sigma_{2} \\ \tau_{12}\end{array}\right]=\left[\begin{array}{ccc}Q_{11} & Q_{12} & 0 \\ Q_{21} & Q_{22} & 0 \\ 0 & 0 & Q_{66}\end{array}\right]\left[\begin{array}{c}\varepsilon_{1} \\ \varepsilon_{2} \\ \gamma_{12}\end{array}\right]$

In any other coordinate system in the plane of the lamina, the $\mathrm{S} / \mathrm{D} / \mathrm{Fes}$ are:

$\mathrm{A}_{11}=\overline{\mathrm{Q}_{11}} \mathrm{t}_{1}+\overline{\mathrm{Q}_{11}} \mathrm{t}_{2}+\overline{\mathrm{Q}_{11}} \mathrm{t}_{3}+\overline{\mathrm{Q}_{11}} \mathrm{t}_{4}$

$\left[\begin{array}{c}\varepsilon_{x^{\circ}} \\ \varepsilon_{y^{\circ}} \\ \gamma_{x y}\end{array}\right]=\left[\begin{array}{lll}a_{11} & a_{12} & a_{16} \\ a_{12} & A_{22} & a_{26} \\ a_{16} & a_{26} & a_{66}\end{array}\right]\left[\begin{array}{c}N_{x} \\ N_{y} \\ N_{x y}\end{array}\right.$
$\left[\begin{array}{c}\varepsilon_{x^{\circ}} \\ \varepsilon_{y^{\circ}} \\ \gamma_{x y}\end{array}\right]=\left[\begin{array}{lll}a_{11} & a_{12} & a_{16} \\ a_{12} & A_{22} & a_{26} \\ a_{16} & a_{26} & a_{66}\end{array}\right]\left[\begin{array}{c}N_{x} \\ N_{y} \\ N_{x y}\end{array}\right]$

$\left[\begin{array}{lll}a_{11} & a_{12} & a_{16} \\ a_{12} & A_{22} & a_{26} \\ a_{16} & a_{26} & a_{66}\end{array}\right]$ = Inverse of $\left[\begin{array}{lll}A_{11} & A_{12} & A_{16} \\ A_{12} & A_{22} & A_{26} \\ A_{16} & A_{26} & A_{66}\end{array}\right]$

$E_{x}=\frac{1}{t}\left[A_{11}-\frac{A_{12}^{2}}{A_{22}}\right]$

$E_{y}=\frac{1}{t}\left[A_{22}-\frac{A_{12}^{2}}{A_{11}}\right]$

For Inner Layers of shaft Buckling Torque is

$T_{c r}=\frac{2.289}{\sqrt{L}} \times\left(E_{x}\right)^{0.375} \times\left(E_{y}\right)^{0.625} \times(t)^{2.25} \times(D)^{1.25}$ 
For outer layer of Shaft Buckling Torque is

$T_{c r}=2 \pi r^{2} t \times 0.272 \times\left[E_{x} \times E_{y}^{3}\right]^{0.25} \times\left[\frac{t}{r}\right]^{1.5}$

$$
\begin{aligned}
& \text { If } \quad \frac{1}{\sqrt{1-\mu^{2}}} \times \frac{L^{2} t}{\left(2 r^{2}\right)}>5.5 \\
& \text { Then, } \tau_{c r}=\frac{E}{3 \sqrt{2}\left(1-\mu^{2}\right)^{3 / 4}} \times\left(\frac{t}{r}\right)^{3 / 2}
\end{aligned}
$$

V. Material Properties

Table .1 Mechanical Properties for Composite and Metal Shaft

\begin{tabular}{|c|c|c|c|c|}
\hline Contain & $\begin{array}{c}\text { Carbon } \\
\text { Epoxy }\end{array}$ & $\begin{array}{c}\text { Glass } \\
\text { Epoxy }\end{array}$ & Steel & Al \\
\hline $\mathrm{E}_{11}$ & $126.9 \mathrm{GPa}$ & $40.3 \mathrm{GPa}$ & $210 \mathrm{GPa}$ & $69 \mathrm{Gpa}$ \\
\hline $\mathrm{E}_{12}$ & $11 \mathrm{GPa}$ & $6.21 \mathrm{GPa}$ & - & - \\
\hline $\mathrm{G}_{12}$ & $6.6 \mathrm{GPa}$ & $3.07 \mathrm{GPa}$ & $80 \mathrm{GPa}$ & $\begin{array}{c}26.5 \\
\mathrm{GPa}\end{array}$ \\
\hline$\mu_{12}$ & 0.2 & 0.2 & 0.3 & 0.3 \\
\hline $\begin{array}{c}\text { Density } \\
\mathrm{Kg} / \mathrm{m}^{3}\end{array}$ & 1610 & 1910 & 7810 & 2700 \\
\hline
\end{tabular}

VI. Finite Element Method

The finite element method is a numerical technique. In this method all the complexities of the problems, like varying shape, boundary conditions and loads are maintained as they are but the solutions obtained are approximate. Because of its diversity and flexibility as an analysis tool, it is receiving much attention in engineering. The fast improvements in computer hardware technology and slashing of cost of computers have boosted this method, since the computer is the basic need for the application of this method. A number of popular brand of finite element analysis packages are now available commercially. Some of the popular packages are STAAD-PRO, GT-STRUDEL, NASTRAN, NISA and ANSYS. Using these packages one can analyze several complex structures. The Finite Element Method (FEM) was developed more by engineers than mathematicians using abstract methods. The FE method is the way of getting a numerical solution to specified problem. The FE analysis does not produce formula as a solution, nor does it solve the class of problems. Also the solution is approximate unless the problem is so simple that convenient exact formula is available.

\section{Finite Element Analysis}

With different fiber angle orientation and Stacking sequence the analysis done in ANSYS 13.0 version for following dimension of hollow composite and steel shaft. For cost purpose we have selected one HM Carbon Epoxy layer and remaining three layers are Glass epoxy. Length of the shaft is $1000 \mathrm{~mm}$, Applied Torque is $350 \mathrm{~N}-\mathrm{m}$. Outer diameter is $104.032 \mathrm{~mm}$, Inner diameter is $100 \mathrm{~mm}$, thickness $\mathrm{t}_{1}=0.1905 \mathrm{~mm}, \mathrm{t}_{2}=0.1905 \mathrm{~mm}$, $\mathrm{t}_{3}=0.635 \mathrm{~mm}, \mathrm{t}_{4}=1.016 \mathrm{~mm}$.

\subsection{SHELL 181 Element}

For analysis purpose SHELL 181 Element is selected. An 4-node element with six degrees of freedom at each node. The element is suitable for analyzing thin to moderately-thick shell structures and is appropriate for linear, large rotation, and/or large strain nonlinear applications. The layer information is input using the section commands rather than real constants.

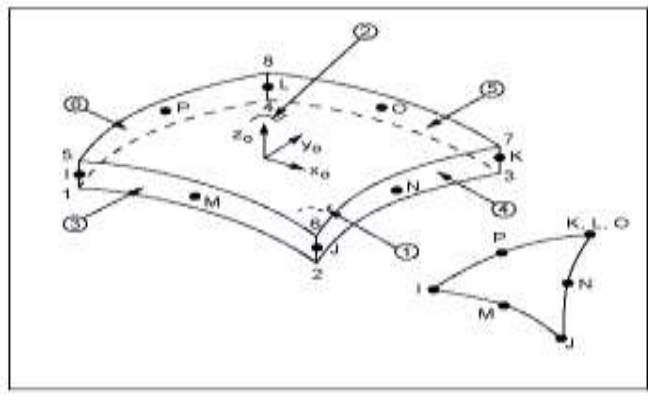




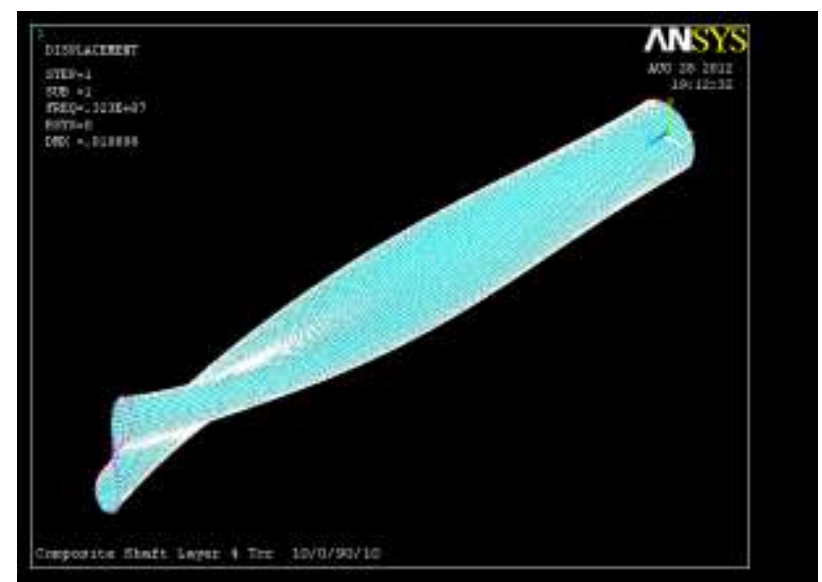

Fig. 1 ANSYS Result for Torsional Buckling Torque for Composite Shaft

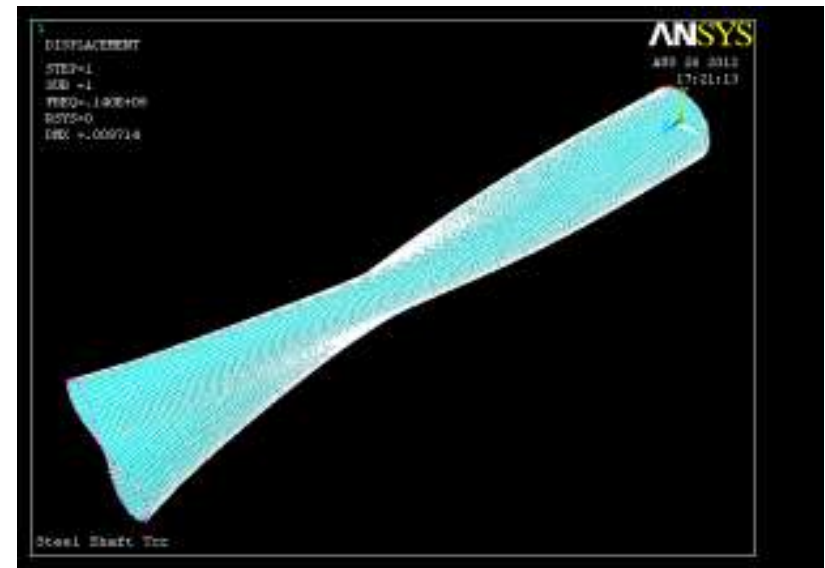

Fig. 2 ANSYS Result for Torsional Buckling Torque for Steel Shaft

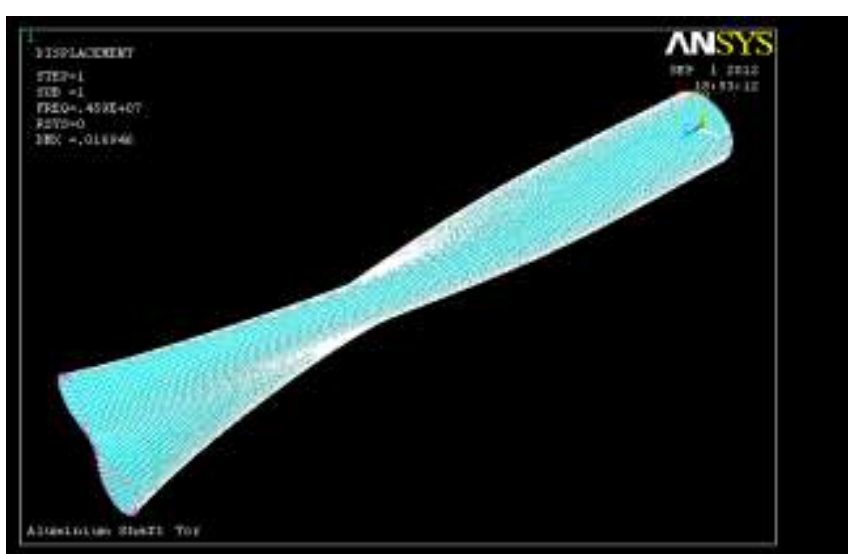

Fig. 3 ANSYS Result for Torsional Buckling Torque for Aluminum Shaft

\section{Result And Discussion}

1. It is found out that there is very minor error occurs in Analytical and in Ansys Method. To obtain optimum Torsional Buckling Torque we combine the fiber angle orientation and compare the Composite Shafts with Metal Shafts.

2. For Torsional Buckling Torque of Drive Shaft the maximum permissible limit is $2.5 \times 10^{6} \mathrm{~N}-\mathrm{mm}$. Hence the Stacking Sequence Glass Epoxy/Glass Epoxy/ Glass Epoxy/ Carbon Epoxy with Fiber Angle Orientation $100 / 00 / 900 / 100$ give the Torsional Buckling Torque $3.23 \times 10^{6} \mathrm{~N}-\mathrm{mm}$ which is beyond the permissible limit. 
Table 2: Torsional Buckling Analysis with ANSYS 13.0 software

\begin{tabular}{|l|l|l|l|}
\hline $\begin{array}{l}\text { Stacking } \\
\text { Sequence }\end{array}$ & $\begin{array}{l}\text { Fibre Angle } \\
\text { Orientation }\end{array}$ & $\begin{array}{l}\text { Torsional } \\
\text { Buckling } \\
\text { Torque } \\
\text { (N-mm) }\end{array}$ & $\begin{array}{l}\text { Weight } \\
\text { of Shaft } \\
\text { (Kg) }\end{array}$ \\
\hline $\mathrm{C} / \mathrm{G} / \mathrm{G} / \mathrm{G}$ & $\begin{array}{l}0^{0} / 90^{0} / \\
90^{0} / 10^{\circ}\end{array}$ & $2.39 \times 10^{6}$ & 1.226 \\
\hline $\mathrm{C} / \mathrm{G} / \mathrm{G} / \mathrm{G}$ & $\begin{array}{l}0^{0} / 90^{\circ} / \\
90^{\circ} / 10^{0}\end{array}$ & $1.76 \times 10^{6}$ & 1.226 \\
\hline $\mathrm{C} / \mathrm{G} / \mathrm{G} / \mathrm{G}$ & $\begin{array}{l}0^{0} / 90^{\circ} / \\
90^{0} / 10^{0}\end{array}$ & $2.01 \times 10^{6}$ & 0.9591 \\
\hline $\mathrm{C} / \mathrm{G} / \mathrm{G} / \mathrm{G}$ & $\begin{array}{l}10^{\circ} / 0^{\circ} / \\
90^{0} / 10^{0}\end{array}$ & $3.23 \times 10^{6}$ & 0.9563 \\
\hline $\begin{array}{l}\text { Steel } \\
\text { Shaft }\end{array}$ & -- & $14 \times 10^{6}$ & 5.087 \\
\hline $\begin{array}{l}\text { Aluminu } \\
\mathrm{m} \text { Shaft }\end{array}$ & -- & $4.59 \times 10^{6}$ & 1.759 \\
\hline
\end{tabular}

Table 3: Torsional Buckling Analysis with Analytical Method.

\begin{tabular}{|l|l|c|l|}
\hline $\begin{array}{l}\text { Stacking } \\
\text { Sequence }\end{array}$ & Fibre Angle Orientation & $\begin{array}{l}\text { Torsional Buckling } \\
\text { Torque }(\mathbf{N}-\mathbf{m m})\end{array}$ & Weight of Shaft $(\mathbf{K g})$ \\
\hline $\mathrm{C} / \mathrm{G} / \mathrm{G} / \mathrm{G}$ & $0^{0} / 90^{0} / 90^{\circ} / 10^{0}$ & $2.48 \times 10^{6}$ & 1.226 \\
\hline $\mathrm{C} / \mathrm{G} / \mathrm{G} / \mathrm{G}$ & $0^{0} / 90^{\circ} / 90^{\circ} / 10^{0}$ & $1.89 \times 10^{6}$ & 1.226 \\
\hline $\mathrm{C} / \mathrm{G} / \mathrm{G} / \mathrm{G}$ & $0^{0} / 90^{\circ} / 90^{\circ} / 10^{0}$ & $2.25 \times 10^{6}$ & 0.9591 \\
\hline $\mathrm{C} / \mathrm{G} / \mathrm{G} / \mathrm{G}$ & $10^{\circ} / 0^{\circ} / 90^{\circ} / 10^{0}$ & $3.39 \times 10^{6}$ & 0.9563 \\
\hline Steel Shaft & -- & $14.03 \times 10^{6}$ & 5.087 \\
\hline Aluminum Shaft & -- & $4.75 \times 10^{6}$ & 1.759 \\
\hline
\end{tabular}

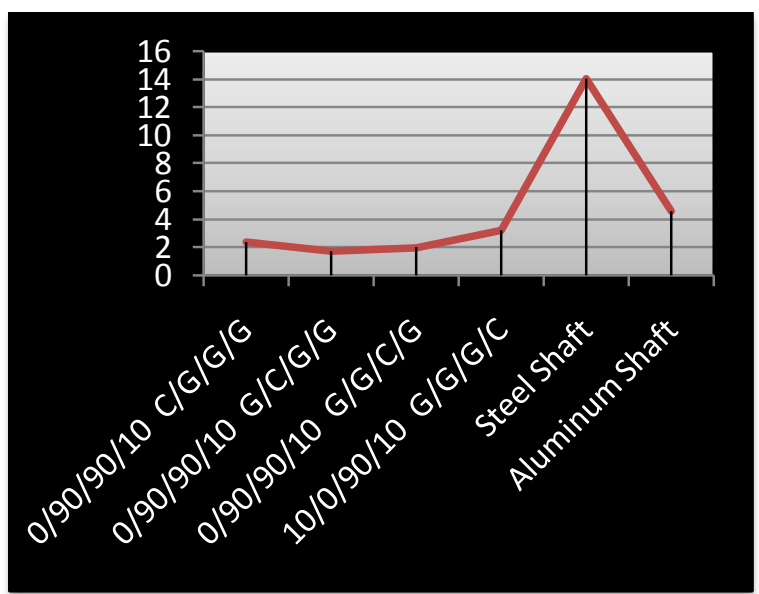

Chart 1: Comparison of Composite Shaft with Metal Shafts for Torsional Buckling Analysis

\section{Conclusion}

It is found out that there is very minor error occurs in Analytical and in Ansys Method. To obtain optimum Torsional Buckling Torque we combine the fiber angle orientation and compare the Composite Shafts with Metal Shafts. For Torsional Buckling Torque of Drive Shaft the maximum permissible limit is $2.5 \times 10^{6}$ N-mm. Hence the Stacking Sequence Glass Epoxy/Glass Epoxy/ Glass Epoxy/ Carbon Epoxy with Fiber Angle Orientation $10^{\circ} / 0^{0} / 90^{\circ} / 10^{\circ}$ give the Torsional Buckling Torque $3.23 \times 10^{6} \mathrm{~N}$-mm which is beyond the permissible limit. The weight is almost reducing $80 \%$ than the steel shaft and $43 \%$ than Aluminum shaft in composite shaft. 


\section{X. $\quad$ Future Scope}

For Different thickness i.e. for Symmetric condition the Composite Shaft can be analysed for further investigation.For further investigation, the composite shaft can be analysed with negative fiber angle orientation.It is possible to investigate the Composite Shaft for more number of layers.It is possible to do the regression analysis for same work.For the same geometry modal analysis to find the natural frequency of composite shaft is possible.

\section{References}

[1] M.A. Badie, E. Mahdi , A.M.S. Hamouda, "An investigation into hybrid carbon /glass fiber reinforced epoxy composite automotive drive shaft", Materials and Design 32 (2011), pp 1485-1500.

[2] Mahmood M. Shokrieh, Akbar Hasani, Larry B. Lessard, "Shear buckling of a composite drive shaft under torsion", Composite Structures 64 (2004), pp 63-69. 3. S.A. Mutasher, "Prediction of the torsional strength of the hybrid aluminum/composite drive shaft", Materials and Design 30 (2009), pp 215-220.

[3] R. Sino, T.N. Baranger, E. Chatelet, G. Jacquet, "Dynamic analysis of a rotating composite shaft", Composites Science and Technology 68 (2008), pp 337-345. 5. Y.A. Khalid, S.A. Mutasher, B.B. Sahari, A.M.S. Hamouda, "Bending fatigue behavior of hybrid aluminum/composite drive shafts", Materials and Design 28 (2007), pp 329-334.

[4] Hak Sung Kim, Dai Gil Lee, "Optimal design of the press fit joint for a hybrid aluminum/composite drive shaft", Composite Structures 70 (2005), pp 33-47.

[5] A.R. Abu Talib, Aidy Ali, Mohamed A. Badie, Nur Azida Che Lah, A.F. Golestaneh, "Developing a hybrid, carbon/glass fiberreinforced, epoxy composite automotive drive shaft", Materials and Design 31 (2010), pp 514-521.

[6] M. A. Badie, A. Mahdi, A. R. Abutalib, E. J. Abdullah and R. Yonus, "Automotive Composite Drive Shafts Investigation of the Design Variable Effects", IJET Vol. 3, No.2, 2006, pp. 227-237.

[7] Nitin Gokhale, Sanjay Deshpande, Anand Thite, Practical Finite Element Analysis, Finite to Infinite, India.

[8] Y. Nakasone, S. YoshimotoT., A. Stolarski, Engineering Analysis With ANSYS Software, First edition 2006, Elsevier ButterworthHeinemann Publication.

[9] Thimmegowda RANGASWAMY, Sabapathy VIJAYARANGAN "Optimal Sizing and Stacking Sequence of Composite Shaft", ISSN 1392-1320, Vol.11 No.2 2005, pp 133-140.

[10] T.Rangaswamy, S. Vijayarangan, R.A. Chandrashekar, T.K. Venkatesh and K.Anantharaman, "Optimal Design and Analysis of Automotive Composite Drive Shaft”, ISRS on Material Science Engineering, December 2002-04, pp 1-9. shaft”, Composite

[11] Robert M. Jones, "Mechanics of Composite Material", Second Edition,USA.

[12] Department of Defense handbook "Composite Materials Handbook", Vol.4. 